\title{
Docetaxel: an alternative taxane in ovarian cancer
}

\author{
N Katsumata ${ }^{1, *}$ \\ 'Department of Medical Oncology, National Cancer Centre Hospital, 5-I-I Tsukiji, Chuo-ku, Tokyo 104-0045, Japan
}

The taxanes paclitaxel and docetaxel are potent chemotherapeutic agents that block tubulin depolymerisation, leading to the inhibition of microtubule dynamics and cell cycle arrest. Although docetaxel and paclitaxel share a mutual tubulin binding site, mechanistic and pharmacological differences exist between these agents. For example, docetaxel has increased potency and an improved therapeutic index compared with paclitaxel, and its short I-h infusion offers a substantial clinical advantage over the prolonged infusion durations required with paclitaxel. In clinical studies, docetaxel monotherapy demonstrated good response rates and an acceptable toxicity profile in both paclitaxel- and platinum-refractory ovarian cancer patients. In particular, neurotoxicity — a dominant side effect with both paclitaxel and cisplatin - occurs at a low incidence with docetaxel, making docetaxel a promising agent for combining cisplatin and other platinum compounds. In Phase II studies, the combination of docetaxel with either cisplatin or carboplatin has yielded impressive response rates of $69-74$ and $81-87 \%$, respectively. Furthermore, Phase III data suggest that docetaxel-carboplatin and paclitaxel-carboplatin are similarly efficacious with respect to progression-free survival and clinical response, although neurotoxicity occurs more frequently with the paclitaxel regimen. While paclitaxel-carboplatin remains the standard treatment for the management of advanced ovarian cancer, docetaxel-carboplatin appears to be a promising alternative, particularly in terms of minimising the incidence and severity of peripheral neuropathy.

British Journal of Cancer (2003) 89 (Suppl 3), S9-SI5. doi:I0.1038/sj.bjc.660I495 www.bjcancer.com

(c) 2003 Cancer Research UK

Keywords: docetaxel; taxanes; ovarian cancer; chemotherapy

Ovarian cancer accounts for nearly $4 \%$ of cancers among women and is the leading cause of gynaecological cancer death in the USA (American Cancer Society, 2003). Indeed, the American Cancer Society estimates that during 2003 a total of 25400 new cases of ovarian cancer will be diagnosed in the USA, and that almost 14300 US women will die from this disease (American Cancer Society, 2003). Platinum-based chemotherapy has been the cornerstone of therapy for advanced ovarian carcinomas since the activity — in the early 1980 s — of cisplatin-based regimens in ovarian cancer was first reported (Decker et al, 1982; Lambert and Berry, 1985; Kaye, 2000). Subsequently, platinum-based combination therapies have been shown to achieve higher clinical response rates and longer progression-free intervals than alkylating agents alone, or nonplatinum regimens, although the evidence for overall survival benefit with such regimens - in cases of advanced ovarian cancer - is less compelling (Aabo et al, 1998). More recently, two large randomised trials, one conducted by the Gynecologic Oncology Group (GOG) and the other by the European Organisation for Research and Treatment of Cancer (EORTC), have shown that administration of the taxane paclitaxel in combination with cisplatin significantly improves the duration of progression-free survival and overall survival in women with advanced epithelial ovarian cancer compared with cisplatin-cyclophosphamide therapy (McGuire et al, 1996; Piccart et al, 2000). Paclitaxel-platinum combinations are therefore replacing platinum-alkylating agent regimens as standard first-line therapy in advanced ovarian cancer (Kaye, 2000). However, since both paclitaxel and cisplatin are

\footnotetext{
*Correspondence: Dr N Katsumata; E-mail: nkatsuma@ncc.go.jp
}

neurotoxic, such combinations are associated with a high degree of neuropathy. Two recently published large randomised trials have shown that paclitaxel-carboplatin achieved comparable efficacy and less toxicity compared with paclitaxel-cisplatin (du Bois et al, 2003; Ozols et al, 2003). It would therefore appear that paclitaxelcarboplatin may provide another first-line chemotherapy regimen for the treatment of advanced ovarian cancer.

Docetaxel is a newer member of the taxoid family, derived by a semisynthetic process from the needles of the European Yew tree Taxus baccata (Denis et al, 1990). This agent has shown significant activity in a variety of cancers including breast, lung, ovarian, head and neck, and gastric cancers. Like paclitaxel, docetaxel acts as a spindle poison, promoting microtubulin assembly and stabilising the polymers against depolymerisation, leading to the inhibition of microtubule dynamics and cell cycle arrest (Ringel and Horwitz, 1991). Although docetaxel and paclitaxel share a mutual tubulin binding site, mechanistic and pharmacological differences exist. For example, preclinical studies have shown that - compared with paclitaxel - docetaxel is a stronger promoter of tubulin polymerisation in vitro, has a longer intracellular half-life and demonstrates greater activity in some tumour models (Barasoain et al, 1991; Ringel and Horwitz, 1991; Bissery et al, 1995).

Docetaxel has demonstrated potent in vitro and in vivo cytotoxic activity against a range of tumour types, particularly ovarian cancer. Indeed, docetaxel was found to be 1.2-2.6 times more cytotoxic than paclitaxel and over 1000 times more cytotoxic than cisplatin or etoposide in ovarian carcinoma cell lines (Kelland and Abel, 1992; Engblom et al, 1997). Docetaxel has also been shown to act synergistically with cisplatin and carboplatin in epithelial ovarian cancer in vitro, and to have potent cytotoxic activity in 
ovarian cell lines that are resistant to these agents (Kelland and Abel, 1992). Furthermore, there is incomplete cross-resistance between paclitaxel and docetaxel in a range of in vitro human tumour cell lines (including ovarian) (Hanauske et al, 1992); and in clinical trials, docetaxel 75 or $100 \mathrm{mg} \mathrm{m}^{-2}$ every 3 weeks has been found to be an active second-line agent in patients refractory to paclitaxel-based regimens (Verschraegen et al, 2000).

Docetaxel and paclitaxel also have substantially different toxicity profiles. Of particular note, docetaxel is associated with only minimal neurotoxicity, which has prompted interest in the use of this agent as an alternative to paclitaxel for inclusion in platinumbased regimens for the management of advanced ovarian cancer (Markman et al, 2001; Vasey on behalf of the Scottish Gynaecological Cancer Trials Group, 2002). In the light of these observations, this paper examines clinical experience to date with docetaxel and discusses the potential of this drug as an alternative to paclitaxel in the management of ovarian cancer.

\section{DOCETAXEL MONOTHERAPY}

\section{Phase I trials}

The clinical efficacy of docetaxel was first reported in Phase I studies in patients with a range of solid tumours (including ovarian cancer) resistant to standard chemotherapy in use at the time of these early trials (Cortes and Pazdur, 1995). These studies identified a short 1-h infusion as the optimal means of delivering docetaxel (Aapro et al, 1992; Bissett et al, 1993; Extra et al, 1993; Cortes and Pazdur, 1995) - offering a substantial clinical advantage over paclitaxel, which requires longer infusion times ( 3 or $24 \mathrm{~h}$ ). Neutropenia was the major toxicity reported with docetaxel in Phase I trials; this was dose- but not scheduledependent (Cortes and Pazdur, 1995). Other side effects included mucositis, hypersensitivity reactions, asthenia and fluid retention, although fluid retention is now routinely prevented by the prophylactic administration of steroids (Cortes and Pazdur, 1995; Kaye et al, 1997; Piccart et al, 1997).

\section{Phase II trials}

The safety and efficacy of docetaxel $100 \mathrm{mg} \mathrm{m}^{-2}$ administered every 3 weeks as a 1-h intravenous infusion have been evaluated in four Phase II trials in women with platinum-refractory advanced ovarian cancer. Two of these studies were multicentre European trials conducted by the Early Clinical Trials Group (ECTG) and the Clinical Screening Group (CSG) of the EORTC, and two were single-centre trials conducted in the USA by the MD Anderson Cancer Center (MDACC) and the Memorial Sloan-Kettering Cancer Center (MSKCC) (Aapro et al, 1994; Francis et al, 1994; Piccart et al, 1995; Kavanagh et al, 1996). A total of 340 patients were included, all of whom had been previously treated with cisplatin or carboplatin and had recurrent or progressive disease. A summary of the characteristics of the patients enrolled in these trials and their response to docetaxel therapy are provided in Table 1.

Overall response rates across the four individual trials ranged from 26 to $40 \%$ (Kaye et al, 1997). When response data from the four trials were pooled, there were 14 complete responses and 79 partial responses among the 315 evaluable patients, giving an overall response rate of 30\% (95\% confidence intervals (CI): 19$36 \%$ ) (Kaye et al, 1997). Importantly, docetaxel maintained this high response rate even in the most platinum-refractory patients, with an overall response rate of $28 \%$ (95\% CI: $19-36 \%$ ) in the 155 patients with a treatment-free interval of less than 4 months. The median duration of response and the median survival in the four individual trials ranged from 4.5 to 6.7 months and from 8 to 10.4 months, respectively. The overall response rates obtained with docetaxel in these four Phase II studies compare favourably with the $22 \%$ response rate reported with paclitaxel in a large population-based study in women with platinum-refractory disease (Trimble et al, 1993).

The toxicity profile of docetaxel was similar across the four trials and reflected observations made in the Phase I studies. Neutropenia was the most frequently reported grade III - IV toxicity ( $90-$ $96 \%$ of patients) and was followed by severe fluid retention, which was experienced by $8-12 \%$ of patients. However, none of these studies included steroid prophylaxis, which has since been shown to reduce significantly the incidence and severity of fluid retention, and also the frequency of treatment discontinuation due to this adverse event. Consequently, routine premedication with a steroid (e.g. dexamethasone) has been incorporated in subsequent docetaxel studies. Other grade III-IV toxicities reported in the four Phase II trials in advanced ovarian cancer included acute hypersensitivity $(7-10 \%$ of patients), diarrhoea (6-10\%),

Table I Efficacy of docetaxel $100 \mathrm{mg} \mathrm{m}^{-2}$ every 3 weeks in women with recurrent or progressive ovarian cancer previously treated with platinum compounds: results from four Phase II studies (adapted from Kaye et al, 1997)

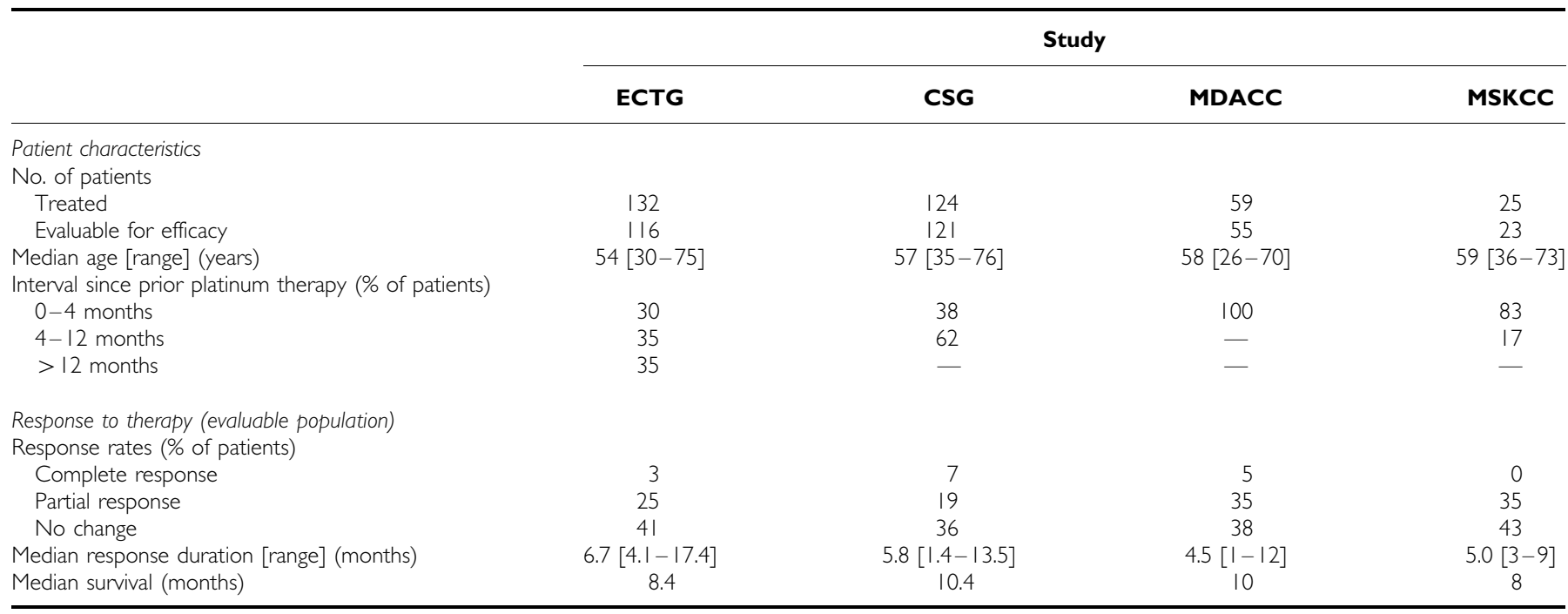

CSG = Clinical Screening Group; ECTG = Early Clinical Trials Group; MDACC = MD Anderson Cancer Center; MSKCC = Memorial Sloan-Kettering Cancer Center. 
dermatitis $(4-8 \%)$ and stomatitis $(0-5 \%)$. From these Phase II studies, it can be concluded that docetaxel demonstrates significant clinical activity against advanced ovarian cancer and has a different spectrum of toxicity to paclitaxel, which is commonly associated with neuropathy and myalgia.

\section{Phase II trials using low-dose docetaxel}

As an alternative to administering prophylactic steroids to reduce the degree of fluid retention, Japanese studies have tended to use lower doses of docetaxel than those used in European and American trials. In a Phase I study conducted in Japan in patients with solid tumours, the maximum tolerated dose of docetaxel without premedication ranged between 70 and $90 \mathrm{mg} \mathrm{m}^{-2}$ (Taguchi et al, 1994). On this basis, the Japanese Phase II programme for docetaxel was initiated at a dose of $60 \mathrm{mg} \mathrm{m}^{-2}$. However, while this dose generated good response rates in women with breast cancer, results in ovarian cancer were disappointing (only one partial response and no complete responses in 36 evaluable patients) (Noda et al, 1994). In a subsequent Phase II pilot study, the dose of docetaxel was increased to $70 \mathrm{mg} \mathrm{m}^{-2}$ every 3 weeks in Japanese women with platinum-pretreated advanced ovarian cancer. This resulted in an acceptable tolerability profile and delivered a response rate of $24 \%$ in the 25 evaluable patients (Fujiwara et al, 1999).

The clinical efficacy and tolerability of docetaxel $70 \mathrm{mg} \mathrm{m}^{-2}$ every 3 weeks in advanced ovarian cancer have since been confirmed in a larger Phase II study in Japan (Katsumata et al, 2000). Here, 60 women previously treated with platinum-based therapies received a median of four courses of docetaxel, $98 \%$ of which were given without the need for dose reduction. Response was achieved in $25 \%$ of platinum-refractory patients (within 0-6 months of the platinum-free interval) and $33 \%$ of platinumsensitive patients (within 6 and more months of the platinum-free interval); the overall response rate was $28 \%$ for all patients combined. Haematological effects were the main toxicities associated with therapy and were recorded at frequencies similar to those observed in European and US Phase II programmes. However, nonhaematological toxicities tended to be milder than had been reported with higher docetaxel dosages. In particular, there was a low incidence of severe hypersensitivity reactions or fluid retention, despite the fact that steroid prophylaxis was not given in this or any other Japanese Phase II trial. Given that the response rates achieved in this trial were similar to those achieved in the higher-dose European and US trials, reducing the docetaxel dosage to $70 \mathrm{mg} \mathrm{m}^{-2}$ may be the preferred chemotherapeutic approach in patients for whom steroid premedication is inappropriate.

\section{DOCETAXEL-PLATINUM: AN ALTERNATIVE FIRST-LINE THERAPY}

\section{Overview of docetaxel-cisplatin trials}

As mentioned previously, the superiority of paclitaxel-cisplatin regimens as first-line chemotherapy over cisplatin-cyclophosphamide therapy (the previous standard of care) has been established in two large randomised trials in women with advanced epithelial ovarian cancer (McGuire et al, 1996; Piccart et al, 2000). One of the major limitations of this combination is that both paclitaxel and cisplatin are neurotoxic, and co-administration of these two agents can result in a high incidence of peripheral neuropathy. This has led several groups, including the French Group d'Investigateurs Nationaux pour l'Etude des Cancers Ovariens (GINECO), the Russian RAMS group and the Scottish Gynaecological Clinical Trials Group (SGCTG), to evaluate the potential of docetaxel as an alternative taxoid to paclitaxel for use in combination with cisplatin in this patient population (Guastalla et al, 1999; Vasey et al, 1999; Gorbounova et al, 2000). In each of these studies, docetaxel $75 \mathrm{mg} \mathrm{m}^{-2}$ and cisplatin $75 \mathrm{mg} \mathrm{m}^{-2}$ were administered every 3 weeks for six courses with routine steroid premedication.

In an interim analysis of the Russian RAMS study, the overall rate of clinical response to docetaxel-cisplatin among the 38 evaluable patients was $73.6 \%$, of which $42.1 \%$ were complete responses and $31.5 \%$ partial responses (Gorbounova et al, 2000); four patients experienced a pathological complete response. In the GINECO trial, docetaxel-cisplatin was associated with a pathological complete response in $21 \%$ of the 43 evaluable patients, and a disease-free survival of 16 months after a median 16 months follow-up (Guastalla et al, 1999). In both trials, docetaxel - cisplatin had an acceptable tolerability profile. No unexpected toxicities were reported (neutropenia was the most common adverse event) and the rates of neurological toxicity and fluid retention were low.

The SGCTG trial differed from the RAMS and GINECO studies in that patients were divided into two treatment cohorts: one receiving cisplatin $75 \mathrm{mg} \mathrm{m}^{-2}$ plus docetaxel $75 \mathrm{mg} \mathrm{m}^{-2}(n=49)$, the other receiving cisplatin $75 \mathrm{mg} \mathrm{m}^{-2}$ plus docetaxel $85 \mathrm{mg} \mathrm{m}^{-2}$ $(n=51)$ (Vasey et al, 1999). In addition, the study was designed primarily to assess the toxicity of the docetaxel-cisplatin combination, its primary end point being the proportion of patients who discontinued therapy because of fluid retention. Only two-thirds of patients completed the full six courses of therapy, with half of all patient withdrawals being attributed to treatmentrelated toxicity. However, no patients withdrew because of fluid retention and only 14 patients (14\%) developed peripheral oedema requiring diuretics, which confirmed previous reports that premedication with a 5-day course of corticosteroids reduces the severity of this adverse event. The incidence of moderate to severe peripheral neuropathy was low ( $6 \%$ grade III). Among the 39 patients who were available for assessment of clinical response after three or six cycles of chemotherapy, $38 \%$ had a complete response and $31 \%$ a partial response.

\section{Overview of docetaxel-carboplatin trials}

There is now a large body of evidence to suggest that in patients with ovarian cancer, carboplatin provides comparable antitumour activity to cisplatin, but with significantly less toxicity when given as monotherapy or in combination with other agents (Aabo et al, 1998). The addition of carboplatin to a taxane regimen was expected to result in less emesis and neurotoxicity than cisplatintaxane therapy, although concerns were expressed that the combined myelotoxicity of carboplatin and a taxane might result in significant myelosuppression, necessitating dose reduction. However, experience with paclitaxel-carboplatin has shown that the two agents can be given safely without reduction in the dosage of either component (Kaye, 2000; du Bois et al, 2003). Indeed, it appears that carboplatin-associated thrombocytopenia is reduced by co-administration of paclitaxel - an effect thought to occur at the level of the megakaryocyte rather than by a general pharmacokinetic interaction (Kaye, 2000). Given these promising results, a series of Phase I/II trials have been conducted to assess docetaxel-carboplatin regimens in this setting, and Phase III trials are underway.

\section{Phase I/II experience}

In a recent Phase I trial of docetaxel and carboplatin as first-line therapy, 22 patients with ovarian cancer were given docetaxel as a 1 -h infusion immediately followed by a 1 -h infusion of carboplatin (Hatae et al, 2002). Dose-limiting toxicities of febrile neutropenia and grade IV diarrhoea were seen at the dose level of docetaxel $75 \mathrm{mg} \mathrm{m}^{-2}$ and carboplatin AUC 6. Pharmacokinetic data for docetaxel were similar to those reported for docetaxel adminis- 
tered as a single agent, and no pharmacokinetic drug-drug interactions were seen. The recommended doses were determined as docetaxel $75 \mathrm{mg} \mathrm{m}^{-2}$ plus carboplatin AUC 5 or docetaxel $70 \mathrm{mg} \mathrm{m}^{-2}$ plus carboplatin AUC 6 .

The efficacy and safety of docetaxel-carboplatin regimens as first-line therapy for epithelial ovarian cancer were first reported by the SGCTG group (Vasey et al, 2001). Their feasibility study included 139 eligible patients (median age 56 years; 79\% FIGO stage III/IV at presentation) treated at one of five docetaxelcisplatin dosage levels, with docetaxel doses ranging between 60 and $85 \mathrm{mg} \mathrm{m}^{-2}$, and carboplatin doses ranging between an area under the concentration-time curve (AUC) of 5 and $7 \mathrm{mg} \mathrm{ml}^{-1}$. Treatment was administered every 3 weeks for six planned cycles, with a 3-day prophylactic dexamethasone regimen. The overall clinical/radiological response rate was 66 , and $75 \%$ of patients had a CA125 response. Median progression-free survival was 16.6 months at a median follow-up of 19 months. Response to therapy at each of the five dosage levels is shown in Figure 1. The incidence of neurotoxicity was extremely low and no patients were removed from the study as a direct result of this side effect. Indeed, grade II/ III sensory neurotoxicity was reported by fewer than $6 \%$ of patients and there were no cases of motor neuropathy of severity greater than grade I; these rates of neuropathy are substantially lower than those reported with paclitaxel-carboplatin regimens. A summary of the neuropathic toxicities reported at the various dosage levels is provided in Figure 2. As anticipated, neutropenia was the major dose-limiting toxicity. CTC grade IV neutropenia occurred in $75 \%$ of patients; however, in only $4 \%$ of patients was this effect associated with sepsis, and prophylactic antibiotics or growth factors were not routinely required. Grade IV thrombocytopenia was seen in only $4.2 \%$ of patients and there were no cases of thrombocytopenic haemorrhage, which suggests that the platelet-sparing effect of paclitaxel when given with carboplatin also extends to docetaxel and is therefore most probably a class effect of the taxoids. On the basis of these results, the dosage regimens recommended by the SGCTG for further trials were docetaxel $75 \mathrm{mg} \mathrm{m}^{-2}$ plus carboplatin AUC 5 or 6 .

The activity and safety of docetaxel $70-75 \mathrm{mg} \mathrm{m}^{-2}$ plus carboplatin to AUC 5-6 every 3 weeks in women with stage III-

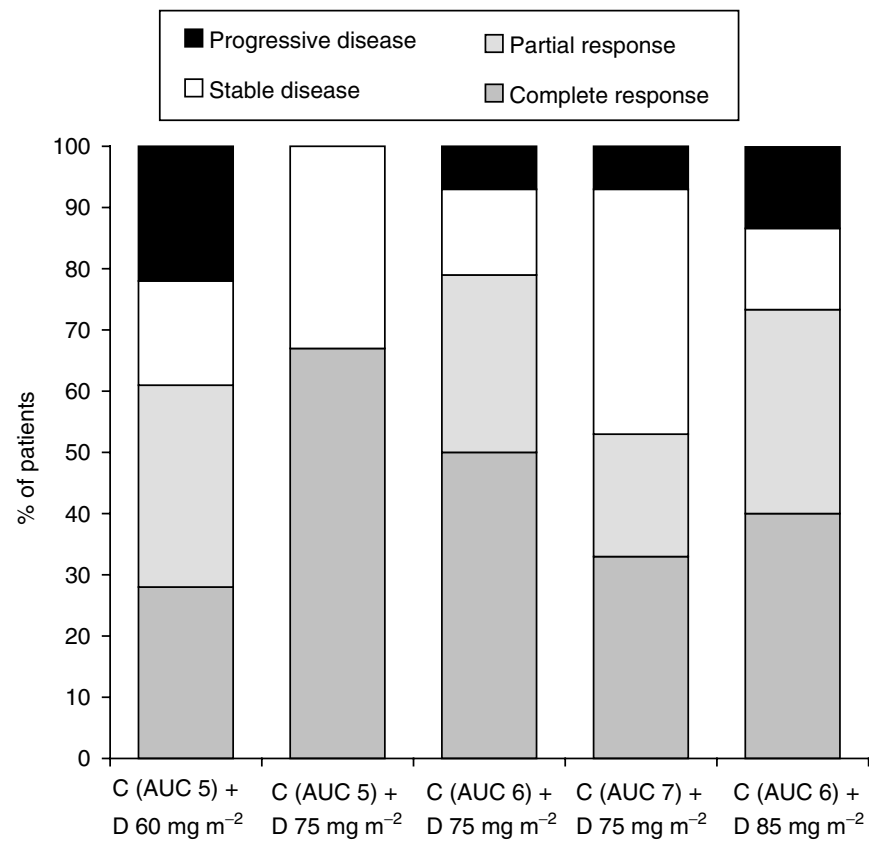

Figure I Response rates to first-line docetaxel (D)-carboplatin (C) therapy in a dose-finding study of D $60-85 \mathrm{mg} \mathrm{m}^{-2}$ and C AUC 5-7 in women with ovarian cancer (73 evaluable for response) (Vasey et al, 200 I).
IV ovarian cancer have been confirmed in three other Phase II studies involving a total of 66 women, 50 of whom were chemonaïve and 16 of whom had received prior platinum-based therapy (Table 2) (Meyer et al, 1999; Kolevska et al, 2001; Vorobiof et al, 2001). In these studies, $27-52 \%$ of patients achieved a complete response and $29-53 \%$ a partial response following docetaxel-carboplatin therapy, with overall response rates ranging from 81 to $87 \%$ (Table 2) (Meyer et al, 1999; Kolevska et al, 2001; Vorobiof et al, 2001). These response rates suggest that this docetaxel-carboplatin regimen is at least as effective as docetaxel-cisplatin regimens.

In all of the studies, neutropenia was the major toxicity. Neurotoxicity was reported in two of the three studies, but the incidence was very low: Kolevska et al (2001) reported grade I neuropathy in seven out of 19 patients, whereas Meyer et al (1999) reported grade II neuropathy in two out of 26 patients and grade I neuropathy in 15 out of 26 patients (no cases of grade III or above). Survival and quality of life data have been reported for one of the three studies - Kolevska and colleagues found that first-line therapy with docetaxel $70 \mathrm{mg} \mathrm{m}^{-2}$ plus carboplatin to AUC 6 every 21 days was associated with a median progression-free survival of 13.1 months in women with cancer of the ovaries, fallopian tube or peritoneum (at the time of the report, median overall survival had not been reached: $9.2+$ months) (Kolevska et al, 2001). Over the course of the study, $50 \%$ of patients experienced a 10-point improvement in the Functional Living Index: Cancer (FLIC) quality of life questionnaire, with $25 \%$ experiencing no change and $25 \%$ experiencing a 10 -point deterioration in FLIC score (Kolevska et al, 2001).

Markman et al (2001) have reported similarly high response rates in a Phase II study employing a lower $60 \mathrm{mg} \mathrm{m}^{-2}$ dose of docetaxel (Table 2). A total of 50 women with cancer of the ovary and fallopian tube and primary cancer of the peritoneum were treated with docetaxel $60 \mathrm{mg} \mathrm{m}^{-2}$ plus carboplatin AUC 6 every 3 weeks for six cycles. The vast majority of patients were chemonaïve (94\%) and had stage III-IV disease (88\%). Of the 42 patients evaluable for efficacy, 34 (81\%) demonstrated objective evidence of a response, with similar response rates being noted in patients with ovarian cancer and those with primary peritoneal cancer. At the time of publication, median progression-free survival had not been reached, but was greater than 16 months. Grade IV neutropenia was the most common toxicity (occurring in $64 \%$ of patients) and neuropathy was reported by only three patients (grade $\mathrm{I}=1$; grade $\mathrm{II}=2)$. Hypersensitivity reactions were relatively common $(34 \%)$ but did not result in the discontinuation of therapy.

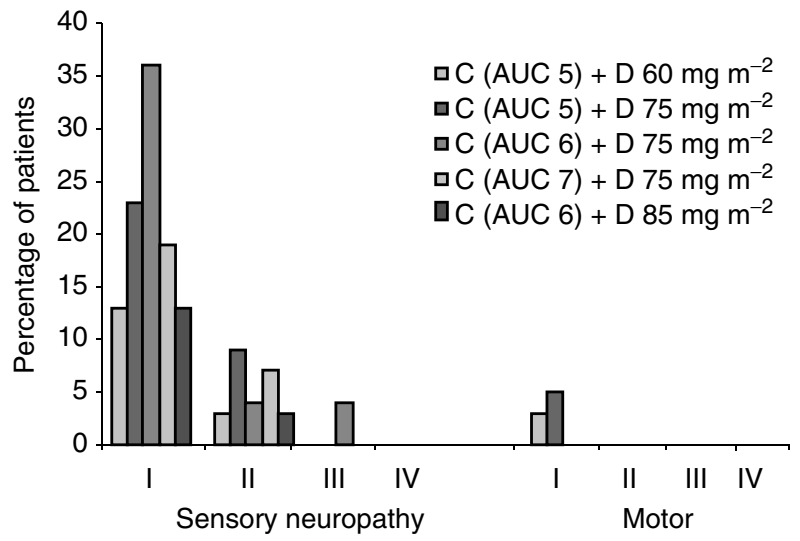

Figure 2 Incidence of neuropathic toxicities reported during first-line docetaxel (D) - carboplatin (C) therapy in a dose-finding study of D 60 $85 \mathrm{mg} \mathrm{m}^{-2}$ and C AUC 5-7 in women with ovarian cancer ( 139 evaluable for safety) (Vasey et al, 200I). 


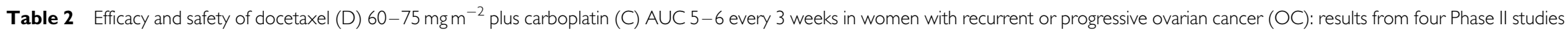
(Meyer et al, 1999; Kolevska et al, 200 I; Markman et al, 200 I; Vorobiof et al, 200I)

\begin{tabular}{|c|c|c|c|c|c|c|c|c|c|c|}
\hline \multirow[b]{2}{*}{ Reference } & \multirow[b]{2}{*}{ Regimen } & \multicolumn{2}{|c|}{ No. of patients evaluable for } & \multirow{2}{*}{$\begin{array}{l}\text { Patient } \\
\text { characteristics at } \\
\text { presentation }\end{array}$} & \multicolumn{3}{|c|}{ Response rate (\% of evaluable patients) } & \multirow{2}{*}{$\begin{array}{l}\text { Length of } \\
\text { follow-up, } \\
\text { median } \\
\text { [range] }\end{array}$} & \multirow{2}{*}{$\begin{array}{l}\text { Progression- } \\
\text { free survival, } \\
\text { median } \\
\text { [range] }\end{array}$} & \multirow{2}{*}{$\begin{array}{l}\text { Toxicity (no. of } \\
\text { patients) }\end{array}$} \\
\hline & & Safety & Efficacy & & CR & PR & Overall & & & \\
\hline Markman et al (200I) & $\begin{array}{l}\text { D } \\
60 \mathrm{mg} \mathrm{m}^{-2}+C \\
\text { AUC } 6 \text { every } \\
21 \text { days for } 6 \\
\text { cycles }\end{array}$ & 50 & 42 & $\begin{array}{l}\text { Chemotherapy-naïe } \\
(94 \%) \text { and platinum- } \\
\text { pretreated }(6 \%) \\
\text { patients with OC (I } 2 \% \\
\text { stage I-II; 88\% stage } \\
\text { III-IV) }\end{array}$ & NS & NS & 81 & $\begin{array}{l}21+\text { months } \\
{[12+\text { to } 4 \mid+]}\end{array}$ & $>16$ months & $\begin{array}{l}\text { Grade IV neutropenia } \\
\text { (32); neutropenic fever } \\
\text { (8); grade III } \\
\text { thrombocytopenia (2); } \\
\text { hypersensitivity (17); } \\
\text { peripheral neuropathy } \\
\text { (3) }\end{array}$ \\
\hline Kolevska et al (200I) & $\begin{array}{l}\text { D } \\
70 \mathrm{mg} \mathrm{m}^{-2}+C \\
\text { AUC } 6 \text { every } \\
21 \text { days for } 6 \\
\text { cycles }\end{array}$ & 19 & 15 & $\begin{array}{l}\text { Chemotherapy-naïve } \\
\text { patients with } \\
\text { suboptimally debulked } \\
\text { stage Illc (63\%) or IV } \\
(37 \%) \text { OC }\end{array}$ & 27 & 53 & $87^{a}$ & $\begin{array}{l}8.9 \text { months } \\
{[0.6-26.4]}\end{array}$ & 13.1 months & $\begin{array}{l}\text { Grade IIIIIV toxicities: } \\
\text { neutropenia (I5); } \\
\text { febrile neutropenia (2); } \\
\text { nausea (2); vomiting } \\
\text { (I); anaemia (2); } \\
\text { thrombocytopenia (3) } \\
\text { oedema (1); weight loss } \\
\text { (I); dehydration (I); } \\
\text { DVT (3); diarrhoea (2) }\end{array}$ \\
\hline Meyer et al (1999) & $\begin{array}{l}\text { D } \\
75 \mathrm{mg} \mathrm{m}^{-2}+C \\
\text { AUC } 5 \text { every } 21 \\
\text { days for } 6 \\
\text { cycles }\end{array}$ & 27 & 27 & $\begin{array}{l}\text { Chemotherapy-naïve } \\
(41 \%) \text { and platinum- } \\
\text { pretreated (59\%) } \\
\text { patients with stage III- } \\
\text { IV OC }\end{array}$ & 52 & 29 & 81 & NS & NS & $\begin{array}{l}\text { Neutropenia (grade II/ } \\
\text { III, 24); } \\
\text { thrombocytopenia } \\
\text { (grade II/II, 7); } \\
\text { neuropathy (grade II, 2) }\end{array}$ \\
\hline Vorobiof et al (200I) & $\begin{array}{l}\text { D } \\
75 \mathrm{mg} \mathrm{m}^{-2}+C \\
\text { AUC 6every } 21 \\
\text { days for } 6 \\
\text { cycles }\end{array}$ & 20 & $11^{c}$ & $\begin{array}{l}\text { Chemotherapy-naïve } \\
\text { patients with stage III- } \\
\text { IV OC }\end{array}$ & 46 & 36 & 82 & NS & NS & $\begin{array}{l}\text { Grade III-IV toxicities } \\
\text { included anaemia, } \\
\text { leucopenia, } \\
\text { neutropenia, } \\
\text { thrombocytopenia, } \\
\text { nausea and vomiting }\end{array}$ \\
\hline
\end{tabular}

${ }^{a}$ Includes one minor response. ${ }^{b}$ Data presented as number of episodes. ${ }^{c}$ Includes patients with measurable disease and excludes those only evaluable for CAI25 response. 


\section{Phase III trial vs paclitaxel}

The efficacy and toxicity profile of docetaxel-carboplatin has been directly compared with that of paclitaxel-carboplatin as first-line therapy for stage Ic-IV epithelial ovarian cancer in an international Phase III randomised trial conducted by the SGCTG. The trial, named SCOTROC (Scottish Randomised Trial in Ovarian Cancer), enrolled 1077 chemonaïve patients between October 1998 and May 2000 from 83 centres in 10 countries. Patients were treated with carboplatin to AUC 5 plus either docetaxel $75 \mathrm{mg} \mathrm{m}^{-2}$ infused over $1 \mathrm{~h}$ or paclitaxel $175 \mathrm{mg} \mathrm{m}^{-2}$ infused over $3 \mathrm{~h}$. Survival and longer-term toxicity results were presented at ASCO 2002 (Vasey on behalf of the Scottish Gynaecological Cancer Trials Group, 2002). These results demonstrate that while the paclitaxel and docetaxel regimens are of similar efficacy, there are significant toxicity differences between the two therapies. The median reported follow-up in surviving patients was 21 months, with $94 \%$ followed up for more than 1 year. Docetaxel-carboplatin achieved similar median progression-free survival to paclitaxelcarboplatin (15.1 vs 15.4 months) and clinical response rates (66 vs $62 \%)$, but the duration of follow-up is currently insufficient to allow survival comparisons. Nevertheless, paclitaxel-carboplatin was associated with a significantly higher rate of grade II/III sensory neuropathy than docetaxel-carboplatin (30 vs $11 \% ; P<$ 0.01 ), while docetaxel-carboplatin resulted in a significantly higher incidence of grade III/IV neutropenia (94 vs 82\%; $P<0.001)$ and febrile neutropenia (10 vs $2 \% ; P<0.001)$, although these events were predictable and easily managed (Vasey on behalf of the Scottish Gynaecological Cancer Trials Group, 2002). Global quality of life parameters based on the EORTC QLQ-C30 instrument were comparable in both arms. However, using the ovarian-specific module OV-028 (Cull et al, 2001), patients reported significantly less severe symptoms of neurotoxicity (using a score based on tingling in hands or feet and numbness in fingers or toes) with docetaxel-carboplatin than with paclitaxel-carboplatin during treatment and also 6 months after randomisation (both $P<0.001$ ).

\section{SUMMARY}

Over the last few years, the combination of a platinum compound such as cisplatin or carboplatin with paclitaxel has emerged as standard chemotherapy for advanced ovarian cancer (Kaye, 2000). Notwithstanding the clinical and survival benefits afforded by these new regimens compared with previous therapies, mortality from advanced ovarian cancer is high. Thus, research into new agents and new combinations continues apace with the objective of improving overall survival and reducing treatment-related toxicity. Docetaxel offers an alternative taxoid treatment to paclitaxel for use in this setting. Indeed, there is preclinical evidence that docetaxel has greater antitumour potency and a better therapeutic index than paclitaxel (Bissery et al, 1995), and its short 1-h infusion also offers a substantial clinical advantage over the 3- or 24-h infusion times required for paclitaxel. In clinical studies, docetaxel monotherapy has demonstrated good response rates and an acceptable toxicity profile in both paclitaxel- and platinumrefractory ovarian cancer patients (Kavanagh et al, 1996; Kaye et al, 1997; Verschraegen et al, 2000). Of particular note, neurotoxicity (a dominant side effect with both paclitaxel and cisplatin) is infrequent and mild with docetaxel, which implies that this drug is a promising new taxane for use in combination with cisplatin and other platinum compounds.

The incorporation of docetaxel into first-line platinum-containing regimens for advanced ovarian cancer has produced successful results. In Phase II studies, overall response rates of $69-74 \%$ were achieved with docetaxel $75 \mathrm{mg} \mathrm{m}^{-2}$ plus cisplatin $75 \mathrm{mg} \mathrm{m}^{-2}$; corresponding rates with docetaxel $75 \mathrm{mg} \mathrm{m}^{-2}$ and carboplatin to AUC 5-6 were $81-87 \%$. The docetaxel-carboplatin combination proved to be better tolerated than the docetaxel-cisplatin combination (Vasey et al, 1999, 2001). A Phase III trial comparing docetaxel-carboplatin with paclitaxel-carboplatin suggests that the two taxane regimens are equally efficacious, but demonstrate clear toxicity differences (Vasey on behalf of the Scottish Gynaecological Cancer Trials Group, 2002). In particular, paclitaxel-carboplatin produced significantly more neurotoxicity, leading to early treatment discontinuation compared with docetaxelcarboplatin. While paclitaxel-carboplatin is currently the standard chemotherapy in the clinical setting, docetaxel-carboplatin is an impressive alternative. It appears that certain patient groups - for example, patients at high risk of developing treatment-related neurotoxicity - may benefit from receiving docetaxel as an alternative to paclitaxel in platinum-based regimens (Markman et al, 2001; Vasey on behalf of the Scottish Gynaecological Cancer Trials Group, 2002).

\section{REFERENCES}

Aabo K, Adams M, Adnitt P, Alberts DS, Barley V, Bell DR, Bianchi U, Bolis G, Brady MF, Brodovsky HS, Bruckner H, Buyse M, Canetta R, Chylak V, Cohen CJ, Colombo N, Conte PF, Crowther D, Edmonson JH, Gennatas C, Gilbey E, Gore M, Guthrie D, Yeap BY (1998) Chemotherapy in advanced ovarian cancer: four systematic meta-analyses of individual patient data from 37 randomized trials. Advanced Ovarian Cancer Trialists' Group. Br J Cancer 78: 1479-1487

Aapro MS, Pujade-Lauraine E, Lhommé C, Fumoleau P, Kerbrat P, Lentz M-A, Azli N (1994) EORTC Clinical Screening Group: phase II study of Taxotere in ovarian cancer (Abstract). Ann Oncol 5(Suppl 5): 508

Aapro MS, Zulian G, Alberto P, Bruno R, Oulid-Aissa D, Le Bail N (1992) Phase I and pharmacokinetic study of RP 56976 in a new ethanol-free formulation of Taxotere. Ann Oncol 3: 53

American Cancer Society (2003) What are the key statistics about ovarian cancer? Available from: URL: http://www.cancer.org/docroot/CRI/content/CRI_2_4_1X_What_are_the_key_statistics_for_ovarian_cancer_33. asp?sitearea $=$ [accessed 6 July 2003]

Barasoain I, De Ines C, Diaz F (1991) Interaction of tubulin and cellular microtubules with Taxotere (RP 56976), a new semisynthetic analog of Taxol (Abstract). Proc AACR 32: 1952

Bissery MC, Vrignaud P, Lavelle F (1995) Preclinical profile of docetaxel (Taxotere), efficacy as a single agent and in combination. Semin Oncol 22: $3-6$
Bissett D, Setanoians A, Cassidy J, Graham MA, Chadwick GA, Wilson P, Auzannet V, Le Bail N, Kaye SB, Kerr DJ (1993) Phase I and pharmacokinetic study of taxotere (RP 56976) administered as a 24hour infusion. Cancer Res 53: $523-527$

Cortes JE, Pazdur R (1995) Docetaxel. J Clin Oncol 13: 2643 - 2655

Cull A, Howat S, Greimel E, Waldenstrom AC, Arraras J, Kudelka A, Chauvenet L, Gould A (2001) Development of a European Organization for Research and Treatment of Cancer questionnaire module to assess the quality of life of ovarian cancer patients in clinical trials: a progress report. Eur J Cancer 37: 47 - 53

Decker DG, Fleming TR, Malkasian Jr GD, Webb MJ, Jeffries JA, Edmonson JH (1982) Cyclophosphamide plus cis-platinum in combination: treatment program for stage III or IV ovarian carcinoma. Obstet Gynecol 60: $481-487$

Denis JN, Correa A, Greene AE (1990) An improved synthesis of the taxol side chain and of RP 56976. J Org Chem 55: 1957-1959

du Bois A, Lück H, Meier W, Adams H-P, Möbus V, Costa S, Bauknecht T, Richter B, Warm M, Schröder W, Olbricht S, Nitz U, Jackisch C, Emons G, Wagner U, Kuhn W, Pfisterer J (2003) A randomized clinical trial of cisplatin/paclitaxel versus carboplatin/paclitaxel as first-line treatment of ovarian cancer. J Natl Cancer Inst 95: 1320-1329

Engblom P, Rantanen V, Kulmala J, Heiskanen J, Grenman S (1997) Taxane sensitivity of ovarian carcinoma in vitro. Anticancer Res 17: $2475-2479$ 
Extra JM, Rousseau F, Bruno R, Clavel M, Le Bail N, Marty M (1993) Phase I and pharmacokinetic study of Taxotere (RP 56976; NSC 628503) given as a short intravenous infusion. Cancer Res 53: 1037-1042

Francis P, Schneider J, Hann L, Balmaceda C, Barakat R, Phillips M, Hakes $\mathrm{T}$ (1994) Phase II trial of docetaxel in patients with platinum-refractory advanced ovarian cancer. J Clin Oncol 12: $2301-2308$

Fujiwara K, Kohno I, Tanaka K, Ogita S, Sasaki Y, Hirabayashi K, Yakushiji M, Tsunematsu R, Terashima Y, Taguchi T, Ohashi Y, Noda K (1999) Phase II dose escalation: a novel approach to balancing efficacy and toxicity of anticancer agents. Japanese Docetaxel Ovarian Cancer Study Group. Anticancer Res 19: 639-644

Gorbounova V, Khokhlova S, Orel N (2000) Docetaxel and cisplatin as firstline chemotherapy in patients with advanced ovarian cancer (Abstract). Proc Am Soc Clin Oncol 20: 1536

Guastalla JP, Ferrero JM, Dieras V (1999) Cisplatin - docetaxel (Taxotere) in first line treatment of advanced ovarian cancer (OC): a GINECO phase II trial (Abstract). Proc Am Soc Clin Oncol 18: 1448

Hanauske AR, Degen D, Hilsenbeck SG, Bissery MC, Von Hoff DD (1992) Effects of Taxotere and taxol on in vitro colony formation of freshly explanted human tumor cells. Anticancer Drugs 3: 121-124

Hatae M, Onishi Y, Nakamura T, Katsumata N, Watanabe T, Andoh M, Kuzuya K, Nawa A, Nakanishi T (2002) Phase I and pharmacokinetic study of docetaxel and carboplatin in epithelial ovarian cancer (Abstract). Proc Am Soc Clin Oncol 21: 2527

Katsumata N, Tsunematsu R, Tanaka K, Terashima Y, Ogita S, Hoshiai H, Kohno I, Hirabayashi K, Yakushiji M, Noda K, Taguchi T (2000) A phase II trial of docetaxel in platinum pre-treated patients with advanced epithelial ovarian cancer: a Japanese cooperative study. Ann Oncol 11: $1531-1536$

Kavanagh JJ, Kudelka AP, de Leon CG, Tresukosol D, Hord M, Finnegan MB, Kim EE, Varma D, Forman A, Cohen P, Edwards CL, Freedman RS, Verschraegen CF (1996) Phase II study of docetaxel in patients with epithelial ovarian carcinoma refractory to platinum. Clin Cancer Res 2: $837-842$

Kaye SB (2000) Intravenous chemotherapy for ovarian cancer - the state of the art? Int J Gynecol Cancer 10: 19-25

Kaye SB, Piccart M, Francis P, Kavanagh J (1997) Phase II trials of docetaxel (Taxotere) in advanced ovarian cancer - an updated overview. Eur J Cancer 33: $2167-2170$

Kelland LR, Abel G (1992) Comparative in vitro cytotoxicity of taxol and Taxotere against cisplatin-sensitive and -resistant human ovarian carcinoma cell lines. Cancer Chemother Pharmacol 30: 444-450

Kolevska T, Smith D, Wertheim I (2001) A phase II study of docetaxel and carboplatin in the treatment of sub-optimally debulked stage III and IV ovarian cancer (Abstract). Proc Am Soc Clin Oncol 20: 2497

Lambert HE, Berry RJ (1985) High dose cisplatin compared with high dose cyclophosphamide in the management of advanced epithelial ovarian cancer (FIGO stages III and IV): report from the North Thames Cooperative Group. BMJ (Clin Res Ed) 290: 889-893

Markman M, Kennedy A, Webster K, Peterson G, Kulp B, Belinson J (2001) Combination chemotherapy with carboplatin and docetaxel in the treatment of cancers of the ovary and fallopian tube and primary carcinoma of the peritoneum. I Clin Oncol 19: 1901-1905

McGuire WP, Hoskins WJ, Brady MF, Kucera PR, Partridge EE, Look KY, Clarke-Pearson DL, Davidson M (1996) Cyclophosphamide and cisplatin compared with paclitaxel and cisplatin in patients with stage III and stage IV ovarian cancer. $N$ Engl J Med 334: 1-6

Meyer A, Huober JB, Goerner R (1999) Chemotherapy with carboplatin/ docetaxel and recurrent epithelial ovarian cancer (Abstract). Proc Am Soc Clin Oncol 20: 1465
Noda K, Terajima Y, Ogita Y, Kono I, Hirabayashi K, Yakushiji M, Taguchi T (1994) Phase II clinical study of RP56976 (docetaxel) in patients with carcinoma ovarii or carcinoma colli uteri. Gan To Kagaku Ryoho 21: $2471-2477$

Ozols RF, Bundy BN, Greer BE, Fowler JM, Clarke-Pearson D, Burger RA, Mannel RS, DeGeest K, Hartenbach EM, Baergen R, Gynecologic Oncology Group (2003) Phase III trial of carboplatin and paclitaxel compared with cisplatin and paclitaxel in patients with optimally resected stage III ovarian cancer: a Gynecologic Oncology Group study. J Clin Oncol 21: $3194-3200$

Piccart MJ, Bertelsen K, James K, Cassidy J, Mangioni C, Simonsen E, Stuart G, Kaye S, Vergote I, Blom R, Grimshaw R, Atkinson RJ, Swenerton KD, Trope C, Nardi M, Kaern J, Tumolo S, Timmers P, Roy JA, Lhoas F, Lindvall B, Bacon M, Birt A, Andersen JE, Zee B, Paul J, Baron B, Pecorelli S (2000) Randomized intergroup trial of cisplatinpaclitaxel versus cisplatin - cyclophosphamide in women with advanced epithelial ovarian cancer: three-year results. J Natl Cancer Inst 92: $699-708$

Piccart MJ, Gore M, Ten Bokkel HW, Van Oosterom A, Verweij J, Wanders J, Franklin H, Bayssas M, Kaye S (1995) Docetaxel: an active new drug for treatment of advanced epithelial ovarian cancer. J Natl Cancer Inst 87: $676-681$

Piccart MJ, Klijn J, Paridaens R, Nooij M, Mauriac L, Coleman R, Bontenbal M, Awada A, Selleslags J, Van Vreckem A, Van Glabbeke M (1997) Corticosteroids significantly delay the onset of docetaxel-induced fluid retention: final results of a randomized study of the European Organization for Research and Treatment of Cancer Investigational Drug Branch for Breast Cancer. J Clin Oncol 15: 3149-3155

Ringel I, Horwitz SB (1991) Studies with RP 56976 (Taxotere): a semisynthetic analogue of taxol. I Natl Cancer Inst 83: 288-291

Taguchi T, Furue H, Niitani H (1994) Phase I clinical trial of RP 56976 (docetaxel), a new anticancer drug. Jpn J Cancer Chemother 21: $1997-$ 2005

Trimble EL, Adams JD, Vena D, Hawkins MJ, Friedman MA, Fisherman JS, Christian MC, Canetta R, Onetto N, Hayn R (1993) Paclitaxel for platinum-refractory ovarian cancer: results from the first 1,000 patients registered to National Cancer Institute Treatment Referral Center 9103. J Clin Oncol 11: 2405-2410

Vasey PA, on behalf of the Scottish Gynaecological Cancer Trials Group (2002) Survival and longer-term toxicity results of the SCOTROC study: docetaxel-carboplatin (DC) vs paclitaxel-carboplatin (PC) in epithelial ovarian cancer (EOC) (Abstract). Proc Am Soc Clin Oncol 20: 804

Vasey PA, Atkinson R, Coleman R, Crawford M, Cruickshank M, Eggleton P, Fleming D, Graham J, Parkin D, Paul J, Reed NS, Kaye SB (2001) Docetaxel-carboplatin as first line chemotherapy for epithelial ovarian cancer. Br J Cancer 84: $170-178$

Vasey PA, Paul J, Birt A, Junor EJ, Reed NS, Symonds RP, Atkinson R, Graham J, Crawford SM, Coleman R, Thomas H, Davis J, Eggleton SP, Kaye SB (1999) Docetaxel and cisplatin in combination as first-line chemotherapy for advanced epithelial ovarian cancer. Scottish Gynaecological Cancer Trials Group. J Clin Oncol 17: $2069-2080$

Verschraegen CF, Sittisomwong T, Kudelka AP, Guedes E, Steger M, Nelson-Taylor T, Vincent M, Rogers R, Atkinson EN, Kavanagh JJ (2000) Docetaxel for patients with paclitaxel-resistant Müllerian carcinoma. $J$ Clin Oncol 18: 2733 - 2739

Vorobiof D, Rapoport B, Mahomed R (2001) A phase II first line study of docetaxel and carboplatin (CBDCA) in patients with ovarian cancer (Abstract). Proc Am Soc Clin Oncol 20: 880 